\title{
Bond behavior of NSM CFRP laminates in concrete under sustained loading
}

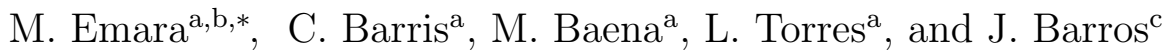 \\ ${ }^{a}$ AMADE, Polytechnic School, Universitat de Girona, Campus Montilivi s/n, 17003 Girona, Spain \\ ${ }^{b}$ Structural Engineering Dept., Faculty of Engineering, Zagazig University, B.O. Box 44519, \\ Zagazig, Sharkia, Egypt. \\ ${ }^{c}$ ISISE, University of Minho, Department of Civil Engineering, Campus de Azurém, 4800-058 \\ Guimarães, Portugal
}

\begin{abstract}
The success of Fiber Reinforced Polymers (FRP) strengthening methodologies for reinforcing concrete structures is highly related to the interfacial bond properties between reinforcement and concrete, which depends upon a number of parameters. Several studies were carried out investigating the short-term bond behavior of Near Surface Mounted (NSM) FRP strengthening systems. However, there has been only limited investigation of its long-term behavior resulting in a significant lack of available experimental data about this relevant aspect. The bond performance of the materials involved in the NSM FRP strengthening system (FRP, adhesive and concrete), due to its nature, is susceptible to be affected by both the sustained loading and environmental conditions. In this study, bond of NSM Carbon FRP (CFRP) laminates in concrete was investigated experimentally using pull-out tests. The experimental program consisted of both short-term tests, in which the load was applied monotonically up to failure, and long-term tests in which different levels of sustained loading were applied. The specimens were tested under sustained loading using bonded length,
\end{abstract}

*Corresponding author. Tel: +34 627114755

Email addresses: mohamed.emara@udg.edu (M. Emara), cristina.barris@udg.edu ( C. Barris), marta.baena@udg.edu (M. Baena ), Lluis.torres@udg.edu (L. Torres ), barros@civil.uminho.pt (and J. Barros) 
adhesive thickness and sustained loading level as the main parameters of the study. Results in terms of slip evolution with time are presented to explore the effects of the studied parameters on the long-term bond behavior between NSM CFRP laminates and concrete. Moreover, an analytical procedure to predict the slip variation versus time is proposed and compared to experimental results.

Keywords: NSM; CFRP; Strips; Pull-out; Sustained load; Bond; Creep 7 poses $[1-5]$.

8

\section{Introduction}

The use of Fiber Reinforced Polymer (FRP) reinforcement in the strengthening of Reinforced Concrete (RC) structures has received considerable attention within the civil and structural engineering fields. Their unique properties, such as the high strength-to-weight ratio and excellent corrosion resistance, make them a suitable and effective alternative to conventional steel for both reinforcing and strengthening purThe most common techniques for strengthening RC structures using FRP materials are those usually known as Externally Bonded Reinforcement (EBR) and Near Surface Mounted (NSM) reinforcement [3, 6-14]. Recently, researchers have shown an increased interest in the NSM technique due to several potential advantages, such as: (i) less prone to debonding from the concrete substrate, (ii) does not require any surface preparation work except grooving, (iii) being the FRP reinforcements better protected by the concrete cover, this technique is then suitable to strengthen the negative moment regions of beams and slabs, and (iv) the aesthetics of a strengthened structure with NSM reinforcement are virtually unchanged [8, 15].

Surveys such as those reported in $[8,16,17]$ showed that Carbon FRP (CFRP) has been used in most existing studies for NSM strengthening of concrete structures. CFRP reinforcement has higher tensile strength and elastic modulus compared to other 
available FRP materials, resulting in some advantages such as: use of smaller crosssectional area, need of smaller groove size, and reduction in the amount of the groove filling material.

Bond between FRP and concrete is a fundamental property that influences the success and the efficiency of the strengthening system as it controls the composite action development between both materials [18-20]. Besides, it affects the load carrying capacity, spacing and width of cracks, as well as the failure mode of the strengthened member [21].

Many parameters may affect the bond behavior and load capacity of the NSM procedure, bonded length, groove size and adhesive properties being among those more influencing [17, 22-28].

Bond tests (direct pull-out and beam-pull out tests) adapted from those existing for steel RC can be used to determine the bond capacity of the strengthening system and concrete splitting resistance along the reinforcement. The direct pull-out test is one of the most common types of bond tests due to its simplicity and advantages: (i) specimens can be easily manipulated, (ii) the area of interest can be easily inspected and (iii) variety of tests specimens and setups can be used [29,30]. Direct pull-out tests can be divided into two main types: single-shear pull-out test, in which one concrete block is used and the FRP reinforcement is bonded to one face of the specimen having the advantage of simple preparation; and double-shear pull-out test, in which one or two concrete blocks are used and the FRP reinforcements are bonded to two opposite faces of the specimen. Although double-shear pull-out test is considered a way to overcome the eccentricity of the reinforcement, single-shear configuration has been more widely used due to its simplicity in preparation and inspection (some issues related to preparation and execution may affect the possible advantages of double-shear configuration: eccentricities, influence of embedded steel bars, or the need to measure 
in both reinforcements). A more detailed analysis of these tests is provided elsewhere $[17,31-34]$. Another issue related to the performance of direct pull-out tests is the presence of compression in the concrete in the most classical setup of the test, which may introduce some confinement affecting the bond performance (also for steel RC). However the possible effect of this confinement may depend on the interrelation between geometrical and mechanical parameters of the test and was not always found to be present [17]. It can be said that most of the studies carried out used the single-shear pullout test due to its simplicity. Although its specific setup may not exactly represent the conditions in strengthened elements, it has been considered an effective method to obtain results able to quantify, check and compare the bond performance of different joint configurations.

A primary concern of strengthened RC structures performance is its long-term bond behavior under serviceability limit state (SLS) conditions, which may be affected by several parameters in case of NSM systems. The impact of adhesive properties on the long-term bond behavior between NSM CFRP strips and concrete was investigated and reported in [35], where the temperature, the adhesive curing time and the initial tensile strip force were the test variables. Results showed that the creep effects were reduced due to the increase in the adhesive curing period, and that the creep was dependent on the stress level in the adhesive layer. In addition, the system performance was affected significantly due to the exposure to high temperature. In the same study, a model to simulate the interaction between adhesive and bond of NSM FRP strips was introduced. The model was based on the non-linear bond-slip law (composed of four different regions) presented in [36] and used for bond of deformed steel bars in concrete. Costa and Barros [37] have investigated experimentally and analytically the creep effects on NSM systems applied with a certain prestress level and concluded that up to sustained stress levels of $60 \%$ the adhesive endured up two times the instantaneous 
strain without rupturing. Since the reduction of the values of the Kelvin components was verified, the time period between adhesive production and its application is a relevant aspect for maintaining the aimed prestress level in the NSM CFRP systems.

With the aim of studying the durability of RC elements strengthened with the NSM technique, Silva et al. [38] experimentally tested beam pull-out and slab specimens strengthened with NSM CFRP strips under sustained loading. Some specimens were kept in the laboratory conditions, others were immersed in water containing $0 \%$ and $3.5 \%$ of chlorides, while others were subjected to wet/dry cycles. The effect of creep was found to be practically negligible in the case of beam pull-out specimens; however, a noticeable creep effect was observed in case of slab specimens.

Derias et al. [39] studied the durability of RC beams strengthened with NSM CFRP strips. Sustained load equal to $40 \%$ of the ultimate load carrying capacity was applied. Some beams were subjected to high temperature, while some others were left in room conditions. Results showed deterioration in the epoxy-concrete interface and changes in failure modes due to the extreme environmental conditions.

On the other hand, numerous works have been carried out to study the long-term bond behavior between CFRP plates Externally Bonded (EB) to concrete blocks. Mazzotti and Savoia [40] tested double shear pull-out specimens under sustained loading equal to $50 \%$ of the ultimate load using three different bonded lengths. Significant redistribution of the shear stresses was observed along the bonded length due to the creep deformation. Based on the experimental results, a simplified model was proposed to predict the evolution of strain and shear stress with time for EBR. The model was developed by using the effective modulus (EM) method, and a linear bond-slip law to model the FRP-concrete anchorage.

Meshgin et al. [41] performed an experimental study in which the effect of applied sustained stress, epoxy thickness and epoxy curing time before loading, on the long- 
term behavior of EB FRP plates was analyzed. Results revealed that the applied sustained stress (as a percentage of the ultimate stress) and the epoxy curing time before loading could be the most critical parameters affecting creep of epoxy at the concrete-FRP interfaces. Similar conclusions were observed in NSM CFRP systems by Costa and Barros [37]. Furthermore, it was observed that more creep was developed as the applied sustained stress increased, so that the application of high sustained stress levels may result in unexpected failures. Based on the experimental results, a modification of the Maxwell creep model was suggested in order to model the longterm behavior of epoxy at the interfaces. By modifying the Burger's model, taking into account the experimental creep test results, Costa and Barros [37] demonstrated the good applicability of this approach for predicting the long-term behavior of NSM CFRP systems.

Dash et al. [42] performed an experimental program concerning the time-dependent deformation of EB CFRP sheets bonded to concrete surface. Single shear pull-out specimens were subjected to sustained loading equal to $40 \%$ of the ultimate load. Some of the specimens were subjected to different environmental conditions of temperature and relative humidity, while some others were immersed in water. Larger creep displacements were observed in case of specimens exposed to elevated temperature with the presence of sustained loading, as well as in those immersed in water compared to those exposed to high humidity.

Results of the study reported in [43] show that, in case of EBR, increasing the thickness of the adhesive layer helped in reducing the peak shear stress over time due to creep. They also observed that transfer length increased with time due to the presence of sustained load.

The long-term bond behavior of strengthened RC structures under SLS conditions is a key aspect that influences the performance of an FRP strengthened RC structure. 
The review of the existing literature provides evidence that up to date there has been limited investigation concerning the long-term bond behavior of NSM FRP strengthening, with the consequent lack of available data and of studies about the effect of the influencing parameters. This paper presents the results of an experimental program aimed to investigate the time-dependent bond behavior between NSM FRP and concrete considering sustained load level, bonded length and adhesive thickness as the main parameters of the study. Results in terms of slip evolution with time are presented and discussed. Moreover, an analytical procedure to predict the slip variation versus time is proposed. The experimental results are satisfactorily compared to those obtained with the proposed model.

\section{Experimental program}

In this experimental program, single shear pull-out specimens were used to obtain the bond-slip response of NSM FRP strengthened elements due to its simplicity, as mentioned previously. Some specimens were tested under monotonic loading up to failure and others under sustained loading. The parameters of the study were the sustained loading level ( $25 \%$ and $50 \%$ of the failure load), the groove width ( 5 and 10 $\mathrm{mm})$ and the bonded length (60,90 and $120 \mathrm{~mm})$. The bonded lengths were selected based on the available literature to introduce bonded lengths shorter, equal and longer than the expected effective bonded length. The effective bonded length of the system was calculated as $90 \mathrm{~mm}$, based on the equations presented in [44], and similar value was reported in [45]. The slip evolution with time under the different loading and environmental conditions were monitored during the test period (i.e. 1000 hours).

For both monotonic pull-out and long-term pull-out test setups, a steel plate having a groove of $30 \mathrm{~mm} \times 30 \mathrm{~mm}$ allowing the CFRP laminate to pass through, was placed at the top of the concrete specimen to restrain its movement when applying the pull- 
out force. An unbonded length of $50 \mathrm{~mm}$ was left from the top of the concrete block to improve the behavior in front of possible premature splitting, confinement stresses and simulation of intermediate crack debonding [18, 31, 46-48].

\subsection{Material properties}

Specimens were cast with ready mixed concrete with compressive strength of 32 $\mathrm{MPa}(\mathrm{CoV} 1.5 \%)$ obtained by testing three concrete cylinders of $150 \mathrm{~mm}$ diameter and $300 \mathrm{~mm}$ height (28 days after casting) in accordance with UNE 12390-3 [49]. The concrete tensile strength and modulus of elasticity were $3 \mathrm{MPa}(\mathrm{CoV} 1.6 \%)$ and 31 GPa (CoV 2\%), respectively. The commercially produced CFRP strips from Clever Reinforcement Iberica with $1.4 \mathrm{~mm}$ thickness and $10 \mathrm{~mm}$ width were used as FRP reinforcing material. The CFRP strips were tested in accordance with ISO 527-5 [50], and a tensile strength of $2400 \mathrm{MPa}(\mathrm{CoV} 3.8 \%)$ and a modulus of elasticity of $160 \mathrm{GPa}(\mathrm{CoV} 2 \%)$ were obtained. According to manufacturer's recommendations, the two components epoxy resin under the commercial name of S\&P220 was used for bonding the laminates to concrete. The tensile strength and modulus of elasticity of the adhesive used were obtained (after 10 days of curing at $20^{\circ} \mathrm{C}$ and $55 \% \mathrm{RH}$ ) in accordance with ISO 527-2 [51], and were found to be $20 \mathrm{MPa}(\mathrm{CoV} 2.3 \%)$ and 6600 $\mathrm{MPa}(\mathrm{CoV} 2.5 \%)$, respectively.

\subsection{Specimen's preparation}

Eighteen concrete blocks with the dimensions equal to $200 \mathrm{~mm} \times 200 \mathrm{~mm} \times 250$ $\mathrm{mm}$, as shown in Fig. 1, were cast and cured under normal laboratory conditions. Once cured, grooves (adapted to the required width and $15 \mathrm{~mm}$ depth) were cut and cleaned with compressed air. Both components of epoxy were mixed, in a proportion of $4 \mathrm{~A}: 1 \mathrm{~B}$ (in weight), until a uniformly gray color (without any streaks) was obtained. Once prepared, the groove was filled with resin to the required bonded length, followed by 

resin was left for curing 10 days before testing at the conditions of $20^{\circ} \mathrm{C}$ and $55 \% \mathrm{RH}$.

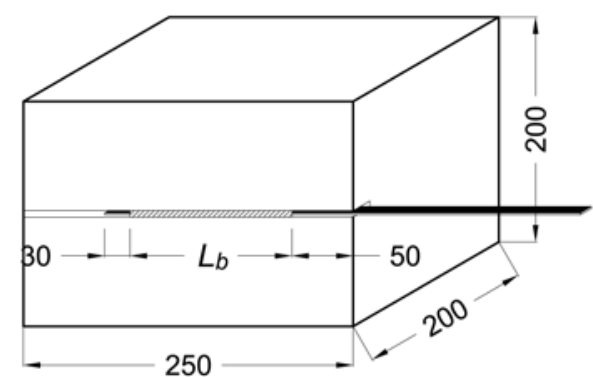

Fig. 1: Test specimen configuration (units in $\mathrm{mm}$ )

176

177 2.3. Monotonic pull-out test

178

the placement of the laminate into the groove. Finally, the surface was leveled and the

Single shear specimens, with three different bonded lengths $\left(L_{b}=60,90\right.$ and 120 $\mathrm{mm}$ ) were tested under direct pull-out shear test (Fig. 2) to obtain their failure loads. For every bonded length, three specimens were tested, thus making a total of nine single shear pull-out tests. Two LVDTs were used to measure the loaded and free end slips. The load was applied using a servo-hydraulic testing machine with displacement controlled rate of $0.2 \mathrm{~mm} / \mathrm{min}$. 


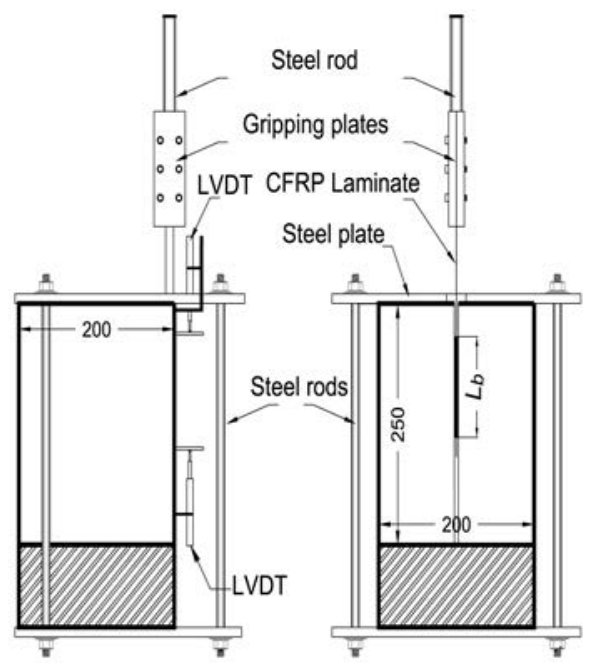

(a)

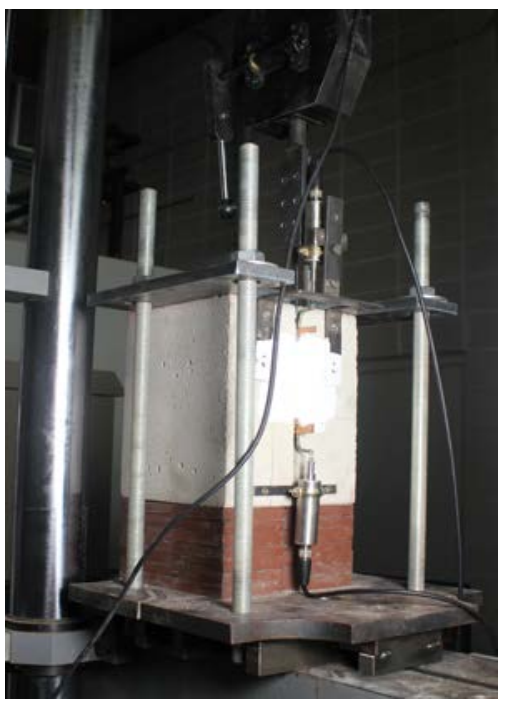

(b)

Fig. 2: (a) Sketch of short-term setup (units in $\mathrm{mm}$ ) and (b) test setup

\subsection{Long-term pull-out test}

A total of nine specimens were tested under sustained loading conditions. Similarly to the short-term tests, three different bonded lengths (60, 90 and $120 \mathrm{~mm}$ ) were considered. The sustained load to be applied was defined as $25 \%$ and $50 \%$ of failure load found in the short-term monotonic pull-out shear tests described in the previous section. The load was applied by means of gravity loading systems through special designed frames as shown in Fig. 3. These frames had a magnification factor of 8.3 and the load was applied by using small concrete blocks. With the aim to analyze the effect of the groove width, three additional tests were performed, whose groove width was doubled. Specimens were kept loaded, for 1000 hours, in a climatic chamber at $20^{\circ} \mathrm{C}$ of temperature and $55 \%$ of relative humidity. Test specimens were identified as follows: the letter $\mathrm{L}$ followed by the bonded length in $\mathrm{mm}$, the letter $\mathrm{S}$ followed by the percentage of applied stress level, and finally, the letter $\mathrm{G}$ followed by the groove width used in mm (see Table 1). The general instrumentation in these long-term pull-out 

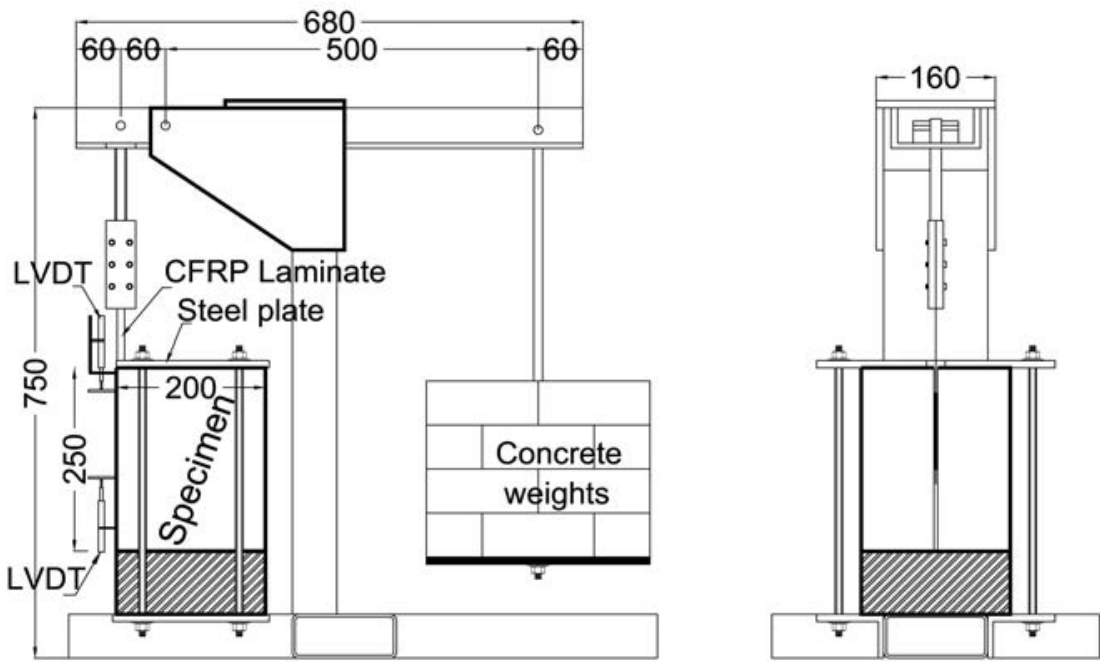

(a)

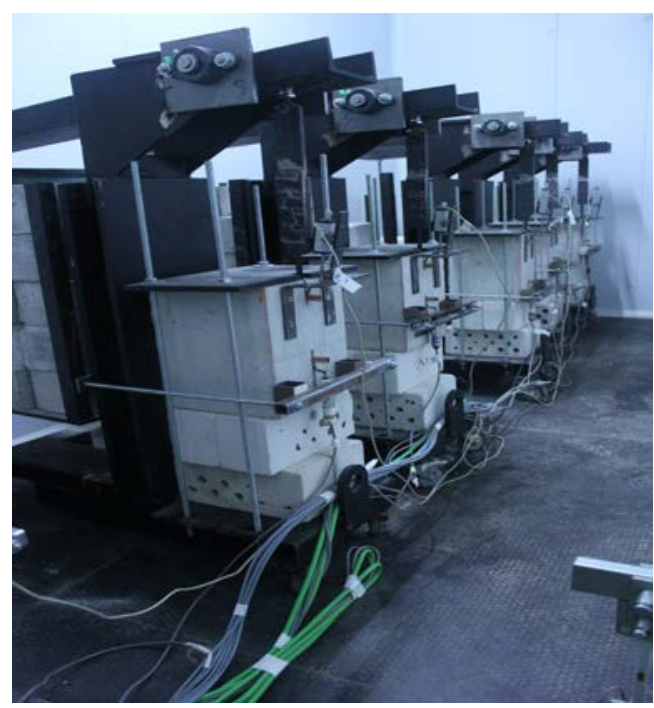

(b)

Fig. 3: (a) Sketch of sustained loading frame (units in $\mathrm{mm}$ ) and (b) test setup 
Table 1: Test matrix.

\begin{tabular}{lccc}
\hline Specimen ID & $\begin{array}{c}\text { Bonded length } \\
(\mathrm{mm})\end{array}$ & $\begin{array}{c}\text { Load level } \\
(\%)\end{array}$ & $\begin{array}{c}\text { Groove width } \\
(\mathrm{mm})\end{array}$ \\
\hline L60S25G5 & 60 & 25 & 5 \\
L90S25G5 & 90 & 25 & 5 \\
L120S25G5 & 120 & 25 & 5 \\
L60S50G5 & 60 & 50 & 5 \\
L90S50G5 & 90 & 50 & 5 \\
L120S50G5 & 120 & 50 & 5 \\
L60S50G10 & 60 & 50 & 10 \\
L90S50G10 & 90 & 50 & 10 \\
L120S50G10 & 120 & 50 & 10 \\
\hline
\end{tabular}

199

\section{Results and discussion}

\subsection{Monotonic loading}

Fig. 4 shows the experimental load-slip curves for the direct short-term tests. Each curve was extracted from average results of specimens tested for each bonded length (60, 90 and $120 \mathrm{~mm}$ ).

The average load carrying capacities were $25 \mathrm{kN}$ for specimens with $L_{b}$ equal to 60 $\mathrm{mm}$ and $30 \mathrm{kN}$ for specimens with $L_{b}$ equal to $90 \mathrm{~mm}$ and $120 \mathrm{~mm}$. Specimens with $L_{b}$ equal to $60 \mathrm{~mm}$ failed by concrete failure, while specimens with $L_{b}$ equal to $90 \mathrm{~mm}$ and $120 \mathrm{~mm}$ showed similar behavior but failing by FRP rupture (see Fig. 5). 


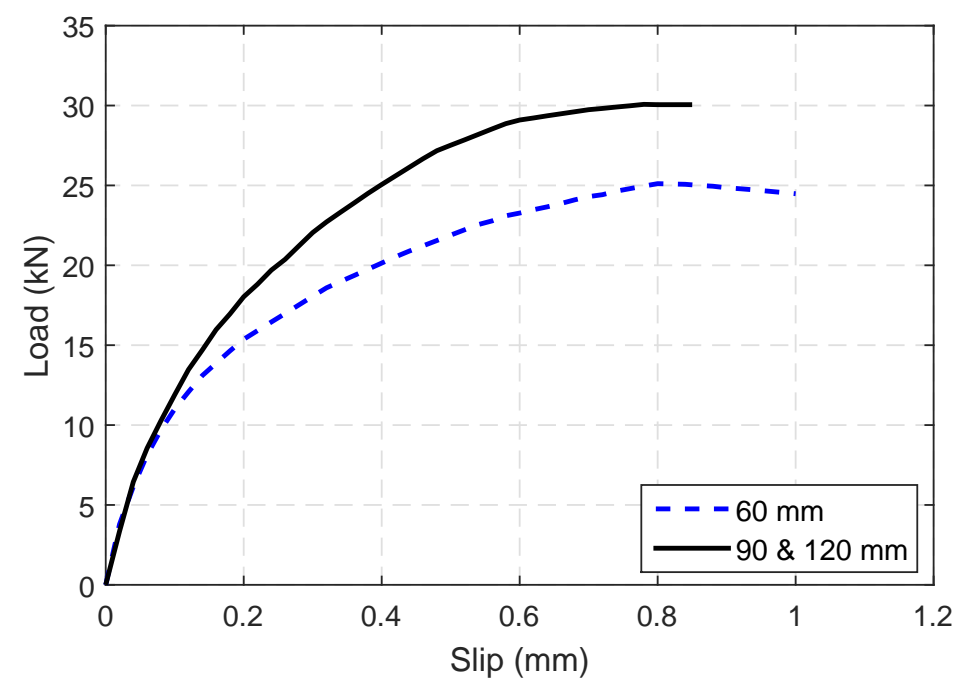

Fig. 4: Load vs. loaded end slip for short-term tests

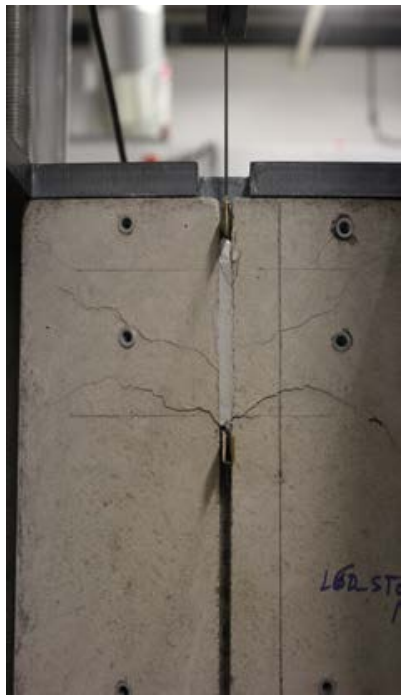

(a)

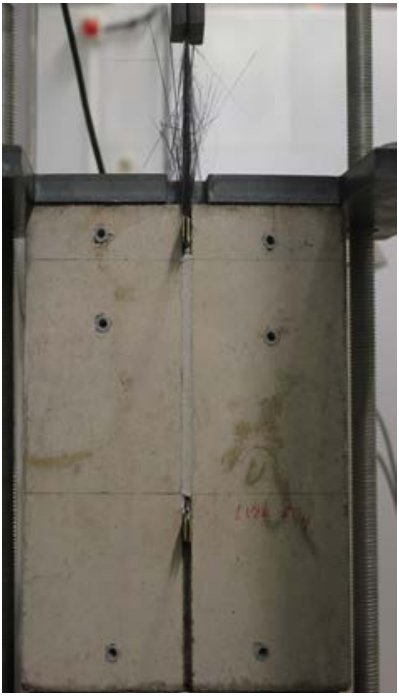

(b)

Fig. 5: Failure modes (a) Concrete failure $\left(L_{b}=60 \mathrm{~mm}\right)$ and (b) CFRP rupture $\left(L_{b}=90\right.$ and $\left.120 \mathrm{~mm}\right)$.

\subsection{Sustained loading}

The total slip values due to sustained loading were registered along the testing period (i.e. 1000 hours) for each specimen. Fig. 6 shows the evolution of the total 

was applied according to the percentage of the failure load.

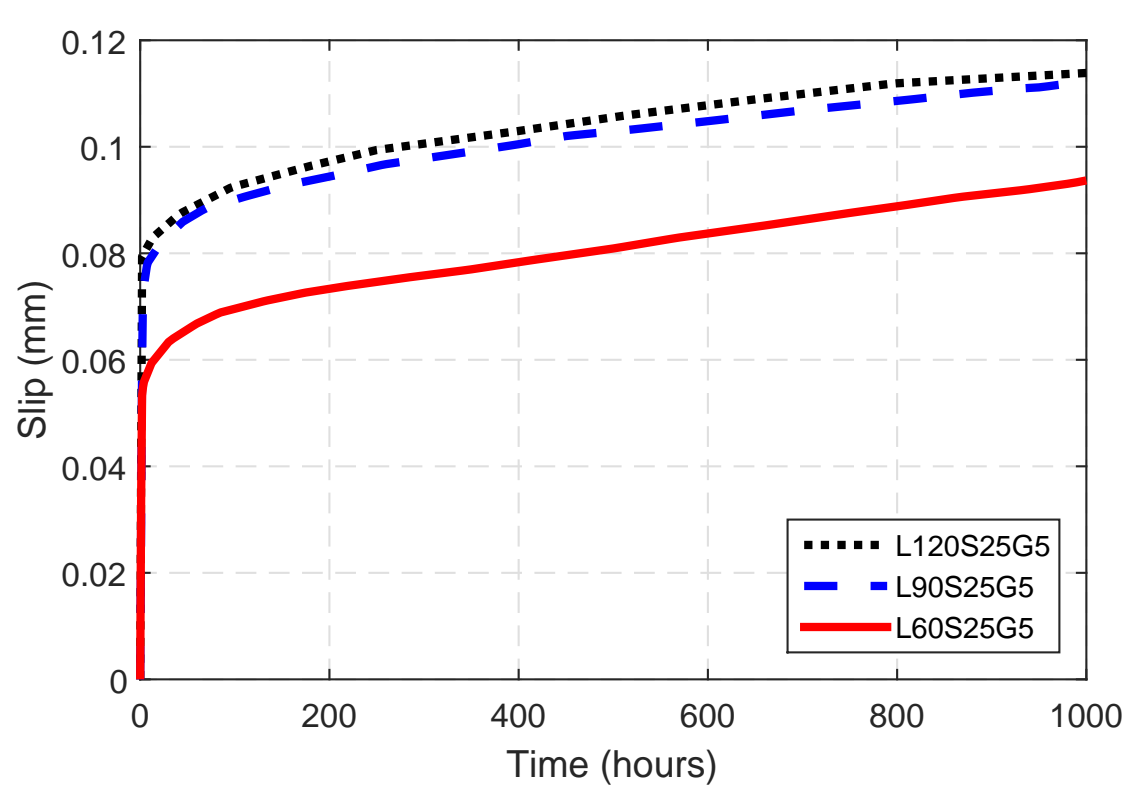

Fig. 6: Total loaded-end slip with time at sustained load level of $25 \%$

loaded-end slip with time due to the application of a sustained loading level equal to $25 \%$ of the failure load. When this sustained load was applied, similar evolution of slip was observed for specimens with bonded length equal to $90 \mathrm{~mm}$ and $120 \mathrm{~mm}$ (i.e. specimens L90S25G5 and L120S25G5, respectively). This similar behavior indicates that the bonded length was not fully activated. For shorter bonded length (i.e. specimen L60S25G5), lower total slip values were obtained as lower value of sustained loading

The experimental slip evolution with time at sustained load level equal to $50 \%$, for the case of specimens with groove width equal to $5 \mathrm{~mm}$, is presented in Fig. 7. Again, similar behavior was observed for specimens having $L_{b}$ equal to $90 \mathrm{~mm}$ and $120 \mathrm{~mm}$, being the initial slip of these specimens larger than that of $L_{b}$ equal to $60 \mathrm{~mm}$, being this observation in agreement with that obtained from the short-term tests. Taken together (i.e. Fig. 6 and Fig. 7), the maintained similarity in the behavior of specimens with $L_{b}$ equal to $90 \mathrm{~mm}$ and $120 \mathrm{~mm}$ indicate that up to sustained loading level equal to $50 \%$ 

groove width equal to $10 \mathrm{~mm}$.

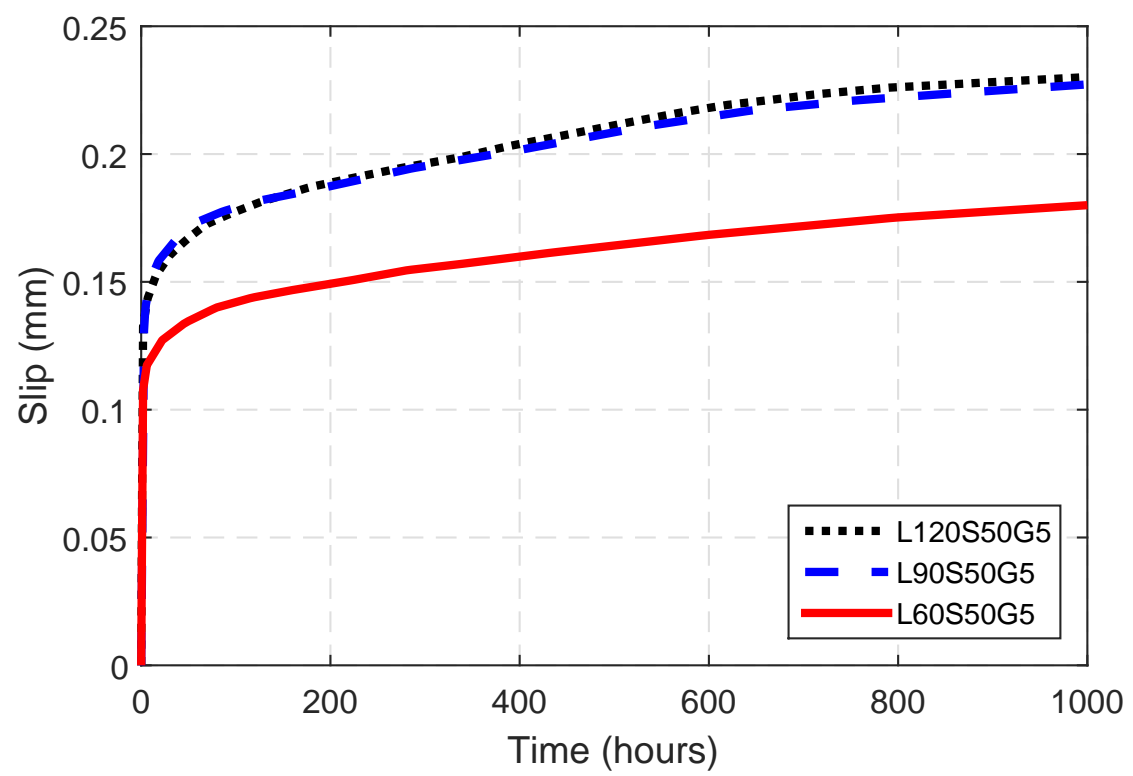

of the failure load, the bonded length was not fully activated. Similar tendencies were observed in case of increasing the groove width at sustained loading equal to $50 \%$ that can be shown in Fig. 8, which illustrates the total slip with time due to the application of sustained loading equal to $50 \%$ of the failure load for the case of specimens with

Fig. 7: Total loaded-end slip with time at sustained load level of $50 \%$ (groove width $=5 \mathrm{~mm}$ )

Fig. 7: Total loaled-end slip with time at sustained load level of $50 \%$ (groove wicth $=5$ min)

When the applied sustained loading level increased from $25 \%$ to $50 \%$, the total slip increased, for all specimens by almost constant ratio of increase along the test period equal to 2.03, 2.06 and 2.07 for specimen with $L_{b}$ equal to $60 \mathrm{~mm}, 90 \mathrm{~mm}$ and $120 \mathrm{~mm}$, respectively. It can be concluded that doubling the sustained loading level, doubled the total slip at any time along the test period. This finding supports results from the monotonic test (Fig. 4) in which up to $50 \%$ of the failure load, the behavior was almost linear. On the other hand, increasing the groove width from $5 \mathrm{~mm}$ to $10 \mathrm{~mm}$ slightly reduced the total slip values for all bonded lengths. This might be attributed to the better and more homogeneous redistribution of shear stress along the bonded length 


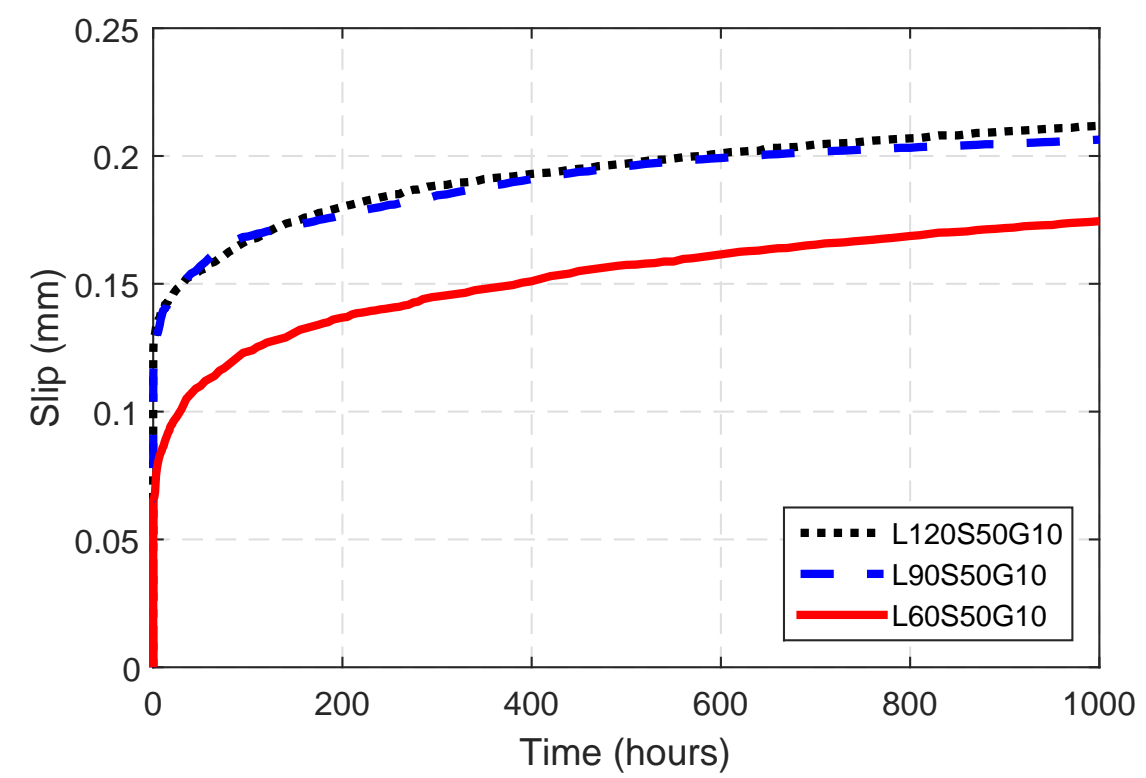

Fig. 8: Total loaded-end slip with time at sustained load level of $50 \%$ (groove width $=10 \mathrm{~mm}$ )

as a result of increasing the adhesive thickness [19, 43]. Increasing the groove width reduced the average total slip by $18 \%, 9 \%$ and $7 \%$ for specimen with $L_{b}$ equal to 60 $\mathrm{mm}, 90 \mathrm{~mm}$ and $120 \mathrm{~mm}$, respectively.

Experimental data presented in this study show that at a sustained load of $25 \%$ of the failure load, the ratio between the total slip at 1000 hours of sustained loading to the instantaneous slip at the time of application of the sustained load $(t=0)$ was found to be 1.77, 1.77 and 1.88 for specimens L60S25G5, L90S25G5 and L120S25G5, respectively. When sustained loading equal to $50 \%$ was applied, similar ratios were obtained with values of $1.75,1.76$ and 1.75 in case of specimens L60S50G5, L90S50G5 and L120S50G5, respectively. On the the other hand, the ratio slightly increased, to be 2.1, 1.82 and 1.83 for specimens L60S50G10, L90S50G10 and L120S50G10, respectively, when the groove width increased from 5 to $10 \mathrm{~mm}$. It was observed that the obtained ratios were almost constant for all cases, however a slight increase was found, as a result of increasing the adhesives volume, when the groove width increased. This slip 
creep increase ratio is directly related to the tensile creep of the adhesive, since for this time period and stress level in the adhesive, Costa and Barros [37] and Emara et al. [52] have measured a tensile strain between two and three times the instantaneous one. No visible changes were appreciated in the appearance of the specimens during the test. By the end of testing period, specimens were unloaded and there were no visible cracks or signs indicating failure either in the concrete or in the epoxy.

\section{Analytical modeling}

In this section a simplified procedure to simulate the long-term behavior, under SLS conditions and sustained loading, of the NSM joint is proposed. First the governing equations for short-term bond behavior are described and then the simulation of the long-term behavior is introduced.

\subsection{Short-term bond behavior}

In a monotonic pull-out test, forces are transferred from reinforcement to concrete through the adhesive by means of shear stresses that appear at their interfaces. Fig. 9 shows an infinitesimal element of CFRP strip of length $d x$, showing the shear stresses at the interface and tensile stresses at the transversal section (of dimensions $h_{f} \mathrm{x} t_{f}$ ).

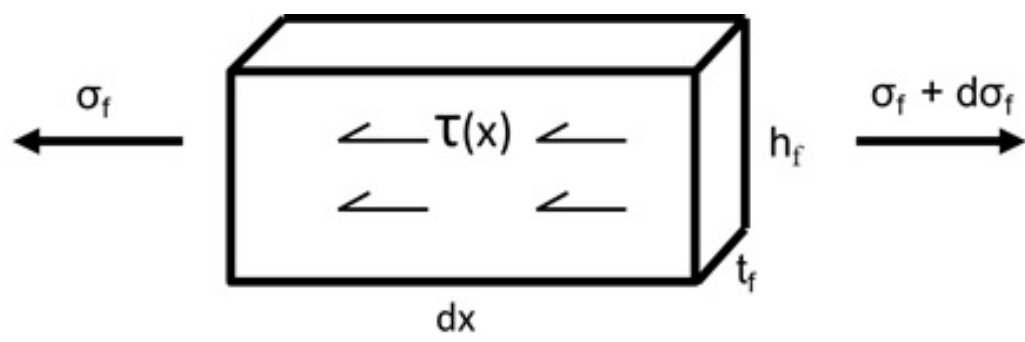

Fig. 9: Infinitesimal element of NSM strip

Equilibrium equation of this infinitesimal element, along with the assumption of CFRP strip having a linear elastic behavior and CFRP-concrete joint being at the 


$$
L_{p}=\left(t_{f}+t_{a}\right)+2\left(h_{f}+t_{a}\right)
$$
width of the FRP strip, respectively (see Fig. 10).

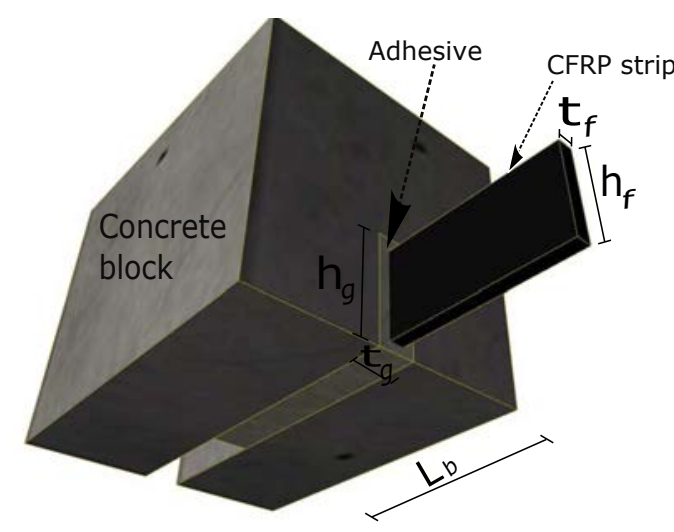

(a)

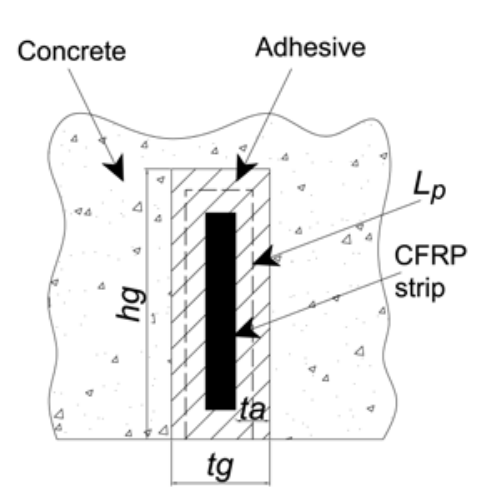

(b)

Fig. 10: (a) NSM system and (b) Details of cross section.

277

278 279

According to the literature $[8,17,40,44,53-59]$, the bond-slip behavior of FRP reinforced elements can be satisfactorily simulated by using a local bilinear law as that 


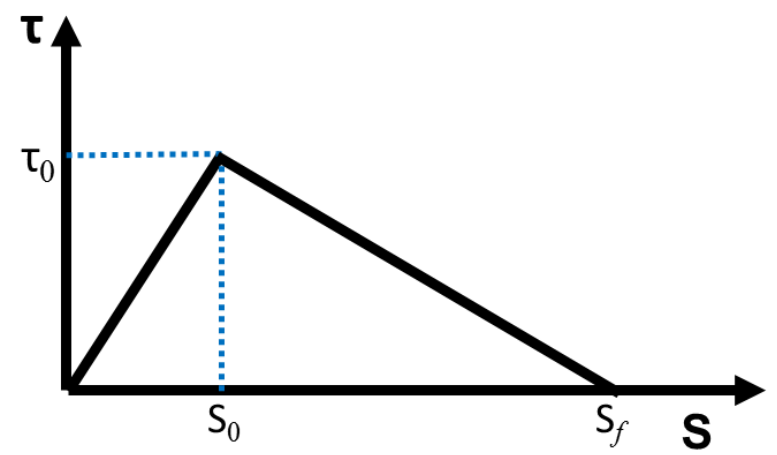

Fig. 11: Bi-linear bond-slip

where $\tau$ and s are the interfacial shear stress and its corresponding slip, respectively, $\tau_{0}$ is the maximum interfacial shear stress, $s_{0}$ is the slip at $\tau_{0}$ and $s_{f}$ is the maximum slip of the $\tau$-s relationship.

This study aimed to simulate the effects of sustained loading under SLS conditions. For this purpose, it was assumed that the slip between CFRP and concrete can be represented by a local bond-slip law applied to the adhesive layer, that the deformability of the concrete can be neglected and that the adhesive is subjected to pure shear [40, 45, 53, 56, 59-61]. The interfacial shear stress in the ascending branch of the bilinear bond-slip law can be obtained by:

$$
\tau=K_{e} s
$$

where $s$ is the slip of the CFRP strip and $K_{e}$ is the stiffness of the $\tau$-s relationship, 
that can be described as:

$$
K_{e}=\tau_{0} / s_{0}
$$

being $\tau_{0}$ and $s_{0}$ the maximum interfacial bond stress in the $\tau$-s relationship and its corresponding slip, respectively.

The first derivative of Eq. 5 yields:

$$
\frac{d \tau}{d x}=K_{e} \varepsilon_{f}
$$

where $\varepsilon_{f}$ is the strains in FRP strip.

By using Eq. 7 and Eq. 1, the following differential equation can be obtained:

$$
\frac{d^{2} \sigma_{f}}{d x^{2}}-\alpha^{2} \sigma_{f}=0
$$

where

$$
\alpha^{2}=\frac{K_{e}}{E_{f} t_{e q}}
$$

being $E_{f}$ is the modulus of elasticity of the FRP.

Eq. 8 can be solved applying the following boundary conditions: at $x=0$ (free end), $\sigma_{f}=0$ and at $x=L$ (loaded end), $\sigma=\sigma_{0}$ (the applied stress in the FRP). After solving the distribution of the axial FRP stress, shear stress and the slip along the bonded length (at any distance $x$ from the free end) are given by:

$$
\sigma_{f}(x)=\sigma_{0} \frac{\sinh (\alpha x)}{\sinh \left(\alpha L_{b}\right)}
$$




$$
\begin{gathered}
\tau(x)=t_{e q} \alpha \sigma_{0} \frac{\cosh (\alpha x)}{\sinh \left(\alpha L_{b}\right)} \\
s(x)=\frac{t_{e q}}{K_{e}} \alpha \sigma_{0} \frac{\cosh (\alpha x)}{\sinh \left(\alpha L_{b}\right)}
\end{gathered}
$$

\subsection{Bond behavior under sustained loading}

The bases of the approach presented in [36] for modelling the long-term bond behavior of steel bars in concrete have been followed in this work, with the difference that the creep effects are introduced here into the bilinear bond-slip model for shortterm behavior of the NSM system previously described (Fig. 11). According to this approach, the evolution of the local bond-slip with time can be estimated based on the initial local bond-slip law and the creep function of the joint, in such a way that slip at any time can be described by:

$$
s(t)=s_{0}\left(1+\phi\left(t, t_{0}\right)\right)
$$

where $\mathrm{s}\left(t_{0}\right)$ and $\mathrm{s}(\mathrm{t})$ are the slip values at time $t_{0}$ and $t$ from loading, respectively, and $\phi\left(t, t_{0}\right)$ is the creep function of the joint at time $\mathrm{t}$ with respect to time $t_{0}$.

The application of this assumption to the short-term bond-slip model (Fig. 11) would cause a shift on the right of the curve for $t_{0}$, resulting in a set of curves for different times as indicated in Fig. 12. Nevertheless, to avoid an unrealistic increment in the available energy under long-term loading (area under the curves), the use of the bond-slip law at time $t_{0}$ as an envelope was proposed, meaning that the maximum available energy corresponds to short-term bond law [36]. Therefore the final set of curves for long-term would correspond to the modified ascending branches for each time $t$ intersecting with the descending branch for short-term as indicated in Fig. 12. This 
assumption was shown to be adequate in previous works using a non-linear bond-slip law composed of four zones, similar to that used for deformed steel bars in concrete $[35]$.

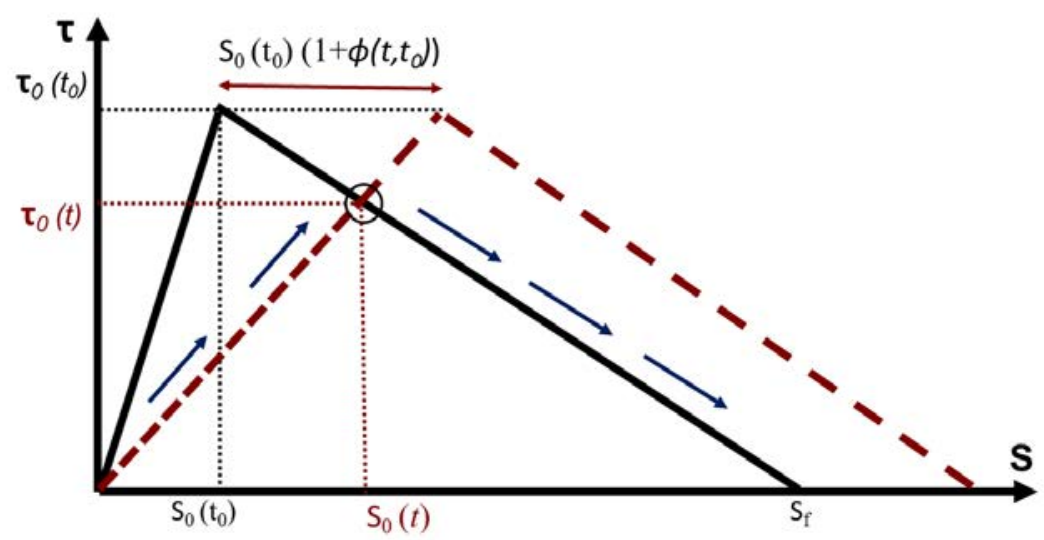

Fig. 12: Bond-slip evolution with time (Arrows show the new bond-slip law at time t)

The practical application of this methodology can be carried out using the socalled Effective Modulus Method (EMM) in which an effective stiffness $K_{e}(t)$ [40] for the ascending branch is used as follows:

$$
K_{e}(t)=\frac{K_{e}\left(t_{0}\right)}{\left(1+\phi\left(t, t_{0}\right)\right)}
$$

$$
\tau_{0}(t)=K_{e}(t) s_{0}(t)
$$

where $K_{e}\left(t_{0}\right)$ and $K_{e}(t)$ are the stiffness of the ascending branch at times $t_{0}$ and $t$, respectively, $\tau_{0}(t)$ and $\phi\left(\mathrm{t}, t_{0}\right)$ are the maximum interfacial shear stress and the creep factor at time $t$, respectively, and $s_{0}(t)$ is the slip corresponding to $\tau_{0}(t)$.

This is represented in Fig. 12 through the reduction in the slope of the ascending branch of the bond-slip relationship at time $t\left(t>t_{0}\right)$. With this reasoning, the time-dependent behavior can be introduced in the analytical equations describing the 
short-term bond problem (Eq. 9 to Eq. 12) just by changing the stiffness with time $\left(K_{e}(t)\right)$

The evolution of bond-slip law with time, presented in Fig. 12, is mainly dependent on the adhesive's properties. These properties can be determined through a tensile creep test that allows for creep coefficients at different times $(\phi(t))$ to be obtained, and therefore, for bond-slip relationships at any time to be determined. Through this procedure, the analytical equations describing the distribution of the axial CFRP stress, the shear stress and the slip along the bonded length with time read:

$$
\begin{gathered}
\alpha^{2}(t)=\frac{K_{e}(t)}{E_{f} t_{e q}} \\
\sigma_{f}(x, t)=\sigma_{0} \frac{\sinh (\alpha(t) x)}{\sinh \left(\alpha(t) L_{b}\right)} \\
\tau(x, t)=t_{e q} \alpha(t) \sigma_{0} \frac{\cosh (\alpha(t) x)}{\sinh \left(\alpha(t) L_{b}\right)} \\
s(x, t)=\frac{t_{e q}}{K_{e}(t)} \alpha(t) \sigma_{0} \frac{\cosh (\alpha(t) x)}{\sinh \left(\alpha(t) L_{b}\right)}
\end{gathered}
$$

Application of previous equations indicate that under sustained loading more creep in the joint develops with time, this leading to reduction in the effective stiffness and consequently more slip takes place along the bonded length and more bonded length is activated. Furthermore, this effect leads to a redistribution of stresses resulting in a decrease of the maximum shear and local concrete stresses. 


\section{Comparison between analytical and experimental results}

The experimental results obtained in the current work are used to check the presented analytical model.

Assuming a short-term load-slip curve as that shown in Fig. 13 and that the axial stiffness of the FRP strip is much smaller than that of the concrete, the maximum bond-stress at time $t_{0}\left(\tau_{0}\left(t_{0}\right)\right)$ can be obtained as $[40,53]$ :

$$
\tau_{0}\left(t_{0}\right)=\frac{P_{\max }^{2}}{L_{p} A_{f} E_{f} s_{f}}
$$

where $P_{\max }$ and $s_{f}$ are the load and slip values at the peak point of the load-slip curve (i.e. point B) at which the interface shear stress reaches its maximum value, and $s_{0}$ is the slip at the end of the linear-elastic part of the curve (point A).

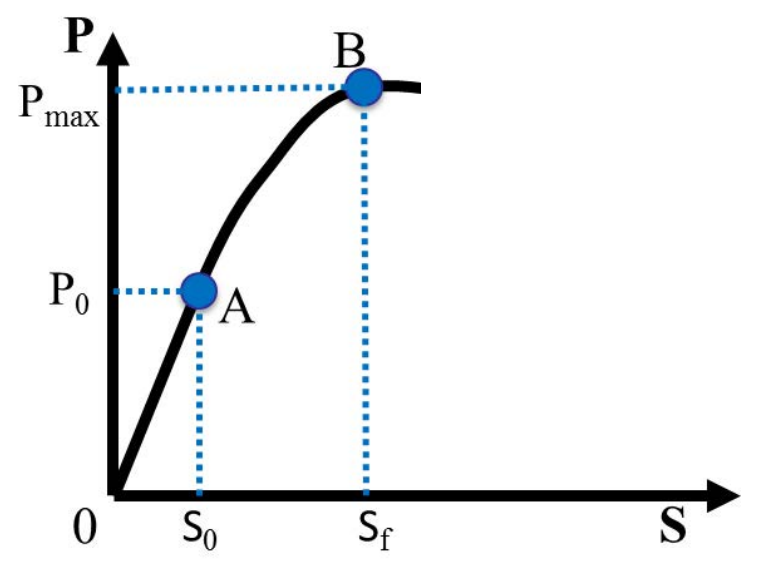

Fig. 13: Load-slip under monotonic loading

The adhesive's creep coefficients were obtained from a tensile creep test carried out by the authors [52] at the same environmental conditions as the pull-out tests and with the same batch of epoxy resin. Experimental values of creep coefficients and the corresponding equivalent stiffness are presented in the second and third columns of Table 2, respectively, while the bond-slip parameters $\left(\tau_{f}(t)\right.$ and $s_{0}(t)$ in Fig. 12) for 
the long-term equivalent curves at different times are indicated in the fourth and fifth columns, respectively.

Table 2: Bond-slip parameters at different times

\begin{tabular}{lcccc}
\hline $\begin{array}{l}\text { Time } \\
\text { (hours })\end{array}$ & $\phi(\mathrm{t})$ & $\begin{array}{c}K_{e}(\mathrm{t}) \\
\left(\mathrm{N} / \mathrm{mm}^{3}\right)\end{array}$ & $\begin{array}{c}\tau_{0}(\mathrm{t}) \\
(\mathrm{MPa})\end{array}$ & $\begin{array}{c}s_{0}(\mathrm{t}) \\
(\mathrm{mm})\end{array}$ \\
\hline 0 & 0 & 229 & 18.35 & 0.08 \\
10 & 0.21 & 189 & 18.04 & 0.10 \\
50 & 0.45 & 158 & 17.71 & 0.11 \\
100 & 0.67 & 137 & 17.41 & 0.13 \\
500 & 1.66 & 86 & 16.20 & 0.19 \\
1000 & 2.40 & 68 & 15.42 & 0.23 \\
\hline
\end{tabular}

364

Once the equivalent stiffness $\left(K_{e}(t)\right)$ has been obtained, analytical predictions of the evolution of slip with time (Eq. 19) are compared to experimental values of the experimental program and presented in Fig. 14 to Fig. 16, for specimens with bonded length of 60, 90 and $120 \mathrm{~mm}$, respectively. As it can be seen, good agreement is in general observed for the analyzed cases, thus indicating that the proposed methodology predicts reasonably well the slip evolution with time.

For the purpose of clarification, Table 3 presents a summary of experimental and predicted values for the loaded-end slips at loading ( $\mathrm{t}=0$ hours) and at the end of the testing period $(t=1000$ hours). The ratios between experimental and predicted slip values are also shown along with the mean and the standard deviation showing good correlation between experimental and analytical results. 


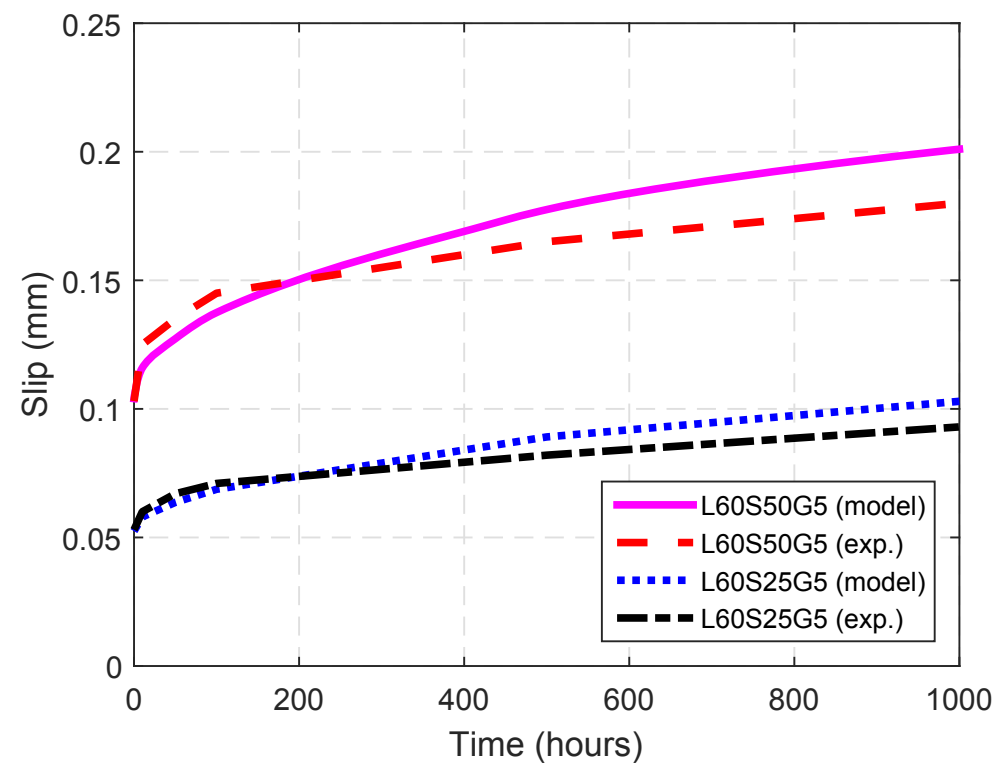

Fig. 14: Comparison of analytical and experimental evolution of slip with time for specimens with $L_{b}=60 \mathrm{~mm}$

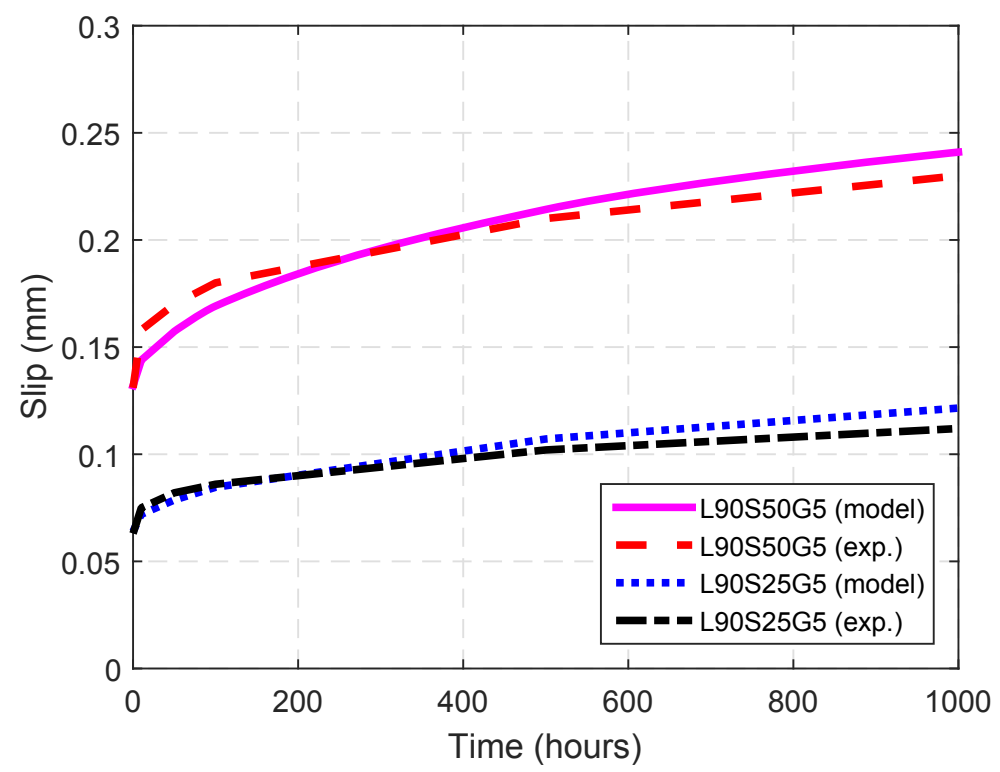

Fig. 15: Comparison of analytical and experimental evolution of slip with time for specimens with $L_{b}=90 \mathrm{~mm}$ 


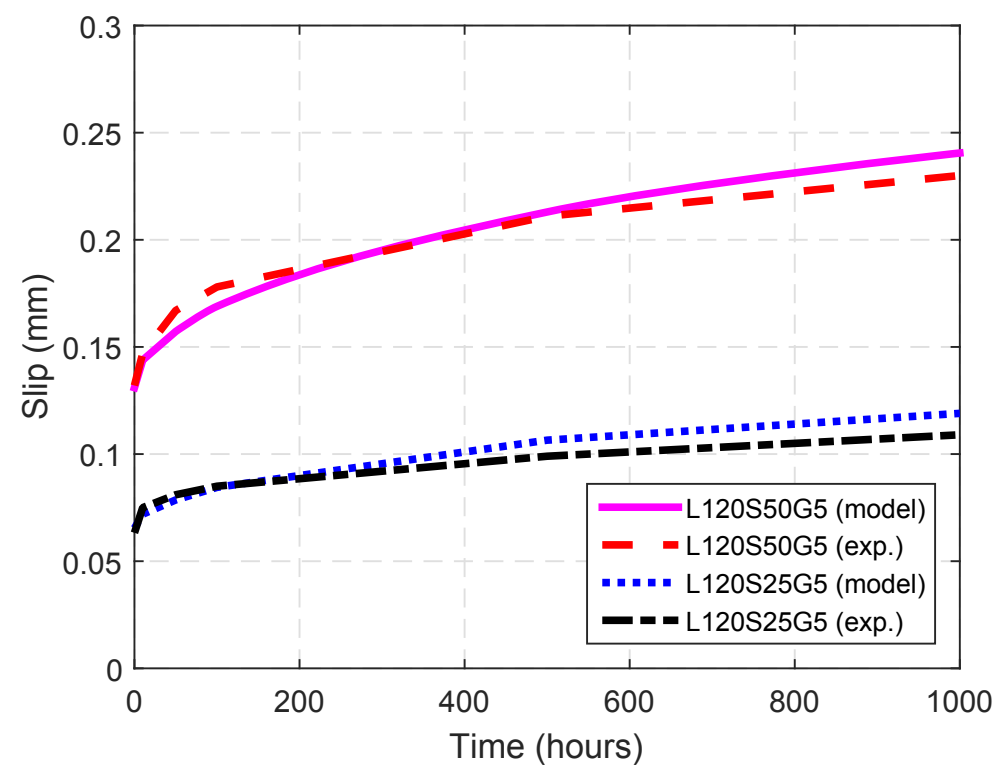

Fig. 16: Comparison of analytical and experimental evolution of slip with time for specimens with $L_{b}=120 \mathrm{~mm}$

Table 3: Comparison between experimental and analytical long-term predictions.

\begin{tabular}{|c|c|c|c|c|c|c|}
\hline Specimen & \multicolumn{3}{|c|}{ loaded-end slip at $\mathrm{t}=0$ hours $(\mathrm{mm})$} & \multicolumn{3}{|c|}{ loaded-end slip at $\mathrm{t}=1000$ hours $(\mathrm{mm})$} \\
\hline & $s_{\text {exp. }}$ & $s_{\text {model }}$ & $s_{\text {model }} / s_{\text {exp. }}$ & $s_{\text {exp. }}$ & $s_{\text {model }}$ & $s_{\text {model }} / s_{\text {exp. }}$ \\
\hline L60S25G5 & 0.053 & 0.052 & 0.98 & 0.094 & 0.103 & 1.10 \\
\hline L60S50G5 & 0.103 & 0.104 & 1.01 & 0.180 & 0.201 & 1.10 \\
\hline L90S25G5 & 0.063 & 0.064 & 1.02 & 0.112 & 0.122 & 1.09 \\
\hline L90S50G5 & 0.131 & 0.132 & 1.01 & 0.230 & 0.241 & 1.04 \\
\hline L120S25G5 & 0.063 & 0.064 & 1.02 & 0.109 & 0.119 & 1.09 \\
\hline L120S50G5 & 0.132 & 0.131 & 0.99 & 0.231 & 0.241 & 1.04 \\
\hline Mean & & & 1.01 & & & 1.06 \\
\hline Standard deviation & & & 0.01 & & & 0.04 \\
\hline
\end{tabular}




\section{Conclusions}

Results of a study designed to investigate the time-dependent bond behavior between NSM FRP and concrete have been presented. Sustained load level (25\% and 50\% of the failure load), bonded length (60,90 and $120 \mathrm{~mm})$ and adhesive thickness were the main parameters studied. A simplified analytical methodology was introduced to predict the time-dependent behavior. From the specimens tested in the current study the following conclusions may be drawn:

- Specimens with bonded length equal to 90 and $120 \mathrm{~mm}$ showed similar behaviors within the same test condition.

- For all bonded lengths used, increasing the sustained loading level from $25 \%$ to $50 \%$ increased the total slip, by almost the double, at any time along the testing period. This observation is coherent with the monotonic test results obtained.

- When the groove width increased from 5 to $10 \mathrm{~mm}$, the total slip values reduced for all bonded lengths. The average reduction was $0.82,0.91$ and 0.93 for specimen with $L_{b}$ equal to 60,90 and $120 \mathrm{~mm}$, respectively.

- The ratio between the total slip at 1000 hours of sustained loading to the instantaneous slip at the time of application of the sustained load $(t=0)$ was found to be similar for all specimens tested. The ratios obtained were 1.77, 1.77 and 1.88 for specimens subjected to sustained loading equal to $25 \%$ with $L_{b}$ equal to 60, 90 and $120 \mathrm{~mm}$, respectively, and 1.75, 1.76 and 1.75 in case of specimens subjected to sustained loading equal to $50 \%$ with $L_{b}$ equal to 60,90 and $120 \mathrm{~mm}$, respectively.

- A simplified analytical methodology has been developed, based on a bi-linear interface model, using the effective modulus method. Good agreement is observed 
between analytical and experimental results.

\section{Acknowledgement}

The authors acknowledge the support provided by the Spanish Government (Ministerio de Economia y Competitividad), Project. BIA2013-46944-C2-2-P. The first author acknowledges the support from the Initial Training Network, Endure, (MCITN-2013- 607851). The authors also wish to acknowledge the support of S\&P Clever Reinforcement Iberica Lda. for supplying the strips and the epoxy resin. The last author wish to acknowledge the grant SFRH/BSAB/114302/2016 provided by FCT.

\section{References}

[1] Balaguru P, Nanni A, Giancaspro J. FRP composites for reinforced and prestressed concrete structures: A guide to fundamentals and design for repair and retrofit. CRC Press; 2008.

[2] Bank LC. Composites for construction: structural design with FRP materials. John Wiley \& Sons; 2006.

[3] Teng J, Chen JF, Smith ST, Lam L. FRP: strengthened RC structures. Frontiers in Physics 2002;1.

[4] fib Bulletin 14 . Externally bonded FRP reinforcement for RC structures. design and use of externally bonded fibre reinforced polymer reinforcement (FRP EBR) for reinforced concrete structures. The International Federation for Structural Concrete (FIB). fib Task Group 9.3 FRP reinforcement for concrete structures. Lausanne, Switzerland; 2001. 
[5] fib Bulletin 40 . FRP reinforcement in RC structures. The International Federation for Structural Concrete (FIB). fib Task Group 9.3, FRP reinforcement for concrete structures. Lausanne, Switzerland; 2007.

[6] Lorenzis LD, Nanni A. Characterization of FRP rods as near-surface mounted reinforcement. Journal of Composites for Construction 2001;5(2):114-21.

[7] Parretti R, Nanni A. Strengthening of RC members using near-surface mounted FRP composites: Design overview. Advances in Structural Engineering 2004;7(6):469-83.

[8] De Lorenzis L, Teng J. Near-surface mounted FRP reinforcement: An emerging technique for strengthening structures. Composites Part B: Engineering 2007;38(2):119-43.

[9] Barros JA, Dias SJ, Lima JL. Efficacy of CFRP-based techniques for the flexural and shear strengthening of concrete beams. Cement and Concrete Composites 2007;29(3):203-17.

[10] Bilotta A, Ceroni F, Di Ludovico M, Nigro E, Pecce M, Manfredi G. Bond efficiency of EBR and NSM FRP systems for strengthening concrete members. Journal of Composites for Construction 2011;15(5):757-72.

[11] Lee D, Cheng L, Yan-Gee Hui J. Bond characteristics of various NSM FRP reinforcements in concrete. Journal of Composites for Construction 2012;17(1):117-29.

[12] Kotynia R. Bond between FRP and concrete in reinforced concrete beams strengthened with near surface mounted and externally bonded reinforcement. Construction and Building Materials 2012;32:41-54. 
[13] Zhang S, Teng JG, Yu T. Bond strength model for CFRP strips near-surface mounted to concrete. Journal of Composites for Construction 2013;18(3):401-3.

[14] Rezazadeh M, Cholostiakow S, Kotynia R, Barros J. Exploring new NSM reinforcements for the flexural strengthening of RC beams: Experimental and numerical research. Composite Structures 2016;141:132-45.

[15] Dalfré GM, Barros JA. NSM technique to increase the load carrying capacity of continuous RC slabs. Engineering Structures 2013;56:137-53.

[16] Szabó ZK, Balázs GL. Near surface mounted FRP reinforcement for strengthening of concrete structures. Periodica Polytechnica Civil Engineering 2007;51(1):33-8.

[17] Coelho MR, Sena-Cruz JM, Neves LA. A review on the bond behavior of FRP NSM systems in concrete. Construction and Building Materials 2015;93:1157-69.

[18] De Lorenzis L, Nanni A. Bond between near-surface mounted fiber-reinforced polymer rods and concrete in structural strengthenings. ACI Structural Journal 2002;99(2):123-32.

[19] Hassan T, Rizkalla S. Investigation of bond in concrete structures strengthened with near surface mounted carbon fiber reinforced polymer strips. Journal of composites for construction 2003;7(3):248-57.

[20] Galati D, De Lorenzis L. Effect of construction details on the bond performance of NSM FRP bars in concrete. Advances in Structural Engineering 2009;12(5):683700.

[21] Teng J, De Lorenzis L, Wang B, Li R, Wong T, Lam L. Debonding failures of RC beams strengthened with near surface mounted CFRP strips. Journal of Composites for Construction 2006;10(2):92-105. 
[22] De Lorenzis L, Lundgren K, Rizzo A. Anchorage length of near-surface mounted fiber-reinforced polymer bars for concrete strengthening - experimental investigation and numerical modeling. ACI Structural Journal 2004;101(2):269-78.

[23] Sena Cruz JM, Oliveira de Barros JA. Bond between near-surface mounted carbonfiber-reinforced polymer laminate strips and concrete. Journal of Composites for Construction 2004;8(6):519-27.

[24] Sena Cruz JM, Barros JA, Gettu R, Azevedo AF. Bond behavior of near-surface mounted CFRP laminate strips under monotonic and cyclic loading. Journal of Composites for Construction 2006;10(4):295-303.

[25] Novidis D, Pantazopoulou S, Tentolouris E. Experimental study of bond of NSMFRP reinforcement. Construction and Building Materials 2007;21(8):1760-70.

[26] Soliman SM, El-Salakawy E, Benmokrane B. Bond performance of near-surfacemounted FRP bars. Journal of Composites for Construction 2010;15(1):103-11.

[27] Sharaky I, Torres L, Baena M, Miàs C. An experimental study of different factors affecting the bond of NSM FRP bars in concrete. Composite Structures 2013;99:350-65.

[28] Torres L, Sharaky IA, Barris C, Baena M. Experimental study of the influence of adhesive properties and bond length on the bond behaviour of NSM FRP bars in concrete. Journal of Civil Engineering and Management 2016;22(6):808-17.

[29] Yan X, Miller B, Nanni A, Bakis C. Characterization of CFRP rods used as near surface mounted reinforcement. 8th International conference on structural faults and repair, Edinburgh (Scotland); 1999, p. CD-ROM version. 
[30] De Lorenzis L, Rizzo A, La Tegola A. A modified pull-out test for bond of near-surface mounted FRP rods in concrete. Composites Part B: Engineering 2002;33(8):589-603.

[31] Szabó, Zsombor Kálmán and Balázs, György L . Importance of boundary conditions on bond of NSM reinforcement. In: rd fib Congress and PCI Annual Convention, May 29 to June 2, Washington DC, USA, full paper on CD-ROM (12 pages). 2010,

[32] Costa I, Barros J. Critical analysis of fibre-reinforced polymer near-surface mounted double-shear pull-out tests. Strain 2013;49(4):299-312.

[33] Bilotta A, Ceroni F, Barros JA, Costa I, Palmieri A, Szabó ZK, et al. Bond of NSM FRP-strengthened concrete: Round robin test initiative. Journal of Composites for Construction 2015;20(1):04015261-16.

[34] Costa I, Barros JA. Assessment of the bond behaviour of nsm frp materials by pullout tests. In: First Middle East Conference on Smart Monitoring, Assessment and Rehabilitation of Civil Structures (SMAR 2011). International Society for Structural Health Monitoring of Intelligent Infrastructure (ISHMII); 2011, p. 1-9.

[35] Borchert K, Zilch K. Bond behaviour of NSM FRP strips in service. Structural Concrete 2008;9(3):127-42.

[36] CEB-1997 . Serviceability models - behaviour and modelling in serviceability limit states including repeated and sustainedloads. CEB, Bulletin d'information No. 235, Lausanne, Switzerland; 1997.

[37] Costa I, Barros J. Tensile creep of a structural epoxy adhesive: Experimental and analytical characterization. International Journal of Adhesion and Adhesives $2015 ; 59: 115-24$. 
[38] Silva P, Fernandes PMG, Sena-Cruz J, Azenha M, Barros JA. Creep behavior and durability of concrete elements strengthened with NSM CFRP strips. In: 7th International Conference on Fiber Reinforced Polymer (FRP) Composites in Civil Engineering (CICE 2014). 2014, p. 1-6.

[39] Derias M, El-Hacha R, Rizkalla S. Durability of NSM FRP strengthening systems for rc flexural members. In: 4th International Conference on Fiber Reinforced Polymer (FRP) Composites in Civil Engineering (CICE 2008), Zurich, Switzerland. 2008,.

[40] Mazzotti C, Savoia M. Stress redistribution along the interface between concrete and FRP subject to long-term loading. Advances in Structural Engineering $2009 ; 12(5): 651-61$.

[41] Meshgin P, Choi KK, Taha MMR. Experimental and analytical investigations of creep of epoxy adhesive at the concrete-FRP interfaces. International Journal of Adhesion and Adhesives 2009;29(1):56-66.

[42] Dash S, Jeong Y, Lopez M, Bakis C. Experimental characterization of moisture, temperature and sustained loading on concrete-FRP bond performance. In: 11th International Symposium on Fiber Reinforced Polymer Reinforcement for Concrete Structures (FRPRCS-11), Guimarães, Portugal. 2013,.

[43] Jeong Y, Lee J, Kim W. Modeling and measurement of sustained loading and temperature-dependent deformation of carbon fiber-reinforced polymer bonded to concrete. Materials 2015;8(2):435-50.

[44] Seracino R, Raizal Saifulnaz M, Oehlers D. Generic debonding resistance of EB and NSM plate-to-concrete joints. Journal of Composites for Construction $2007 ; 11(1): 62-70$. 
[45] Sena Cruz JS, Barros J. Modeling of bond between near-surface mounted CFRP laminate strips and concrete. Computers \& Structures 2004;82(17):1513-21.

[46] Seracino, Rudolf and Jones, Nicola M and Ali, MS and Page, Mark W and Oehlers, Deric J . Bond strength of near-surface mounted FRP strip-to-concrete joints. Journal of Composites for Construction 2007;11(4):401-9.

[47] Sena-Cruz, José and Silva, Patrícia and Fernandes, Pedro Miguel Gomes and Azenha, Miguel and Barros, Joaquim AO and Sousa, Christoph Fernandes and Castro, Fernando and Teixeira, Tiago André Nunes . Creep behavior of concrete elements strengthened with NSM CFRP laminate strips under different environmental conditions. In: FRPRCS-11: 11th International Symposium on Fiber Reinforced Polymer for Reinforced Concrete Structures. Universidade do Minho; 2013, p. $1-12$.

[48] Fernandes, Pedro MG and Silva, Patrícia M and Sena-Cruz, José . Bond and flexural behavior of concrete elements strengthened with NSM CFRP laminate strips under fatigue loading. Engineering Structures 2015;84:350-61.

[49] UNE-EN-12390-3 . Testing hardened concrete - part 3: Compressive strength of test specimens. AENOR- Asociación Española de Normalización y Certificación; 2003.

[50] ISO-527-5 . Plastics - determination of tensile properties - part 5: Test conditions for unidirectional fibre-reinforced plastic composites. ISO International Organization for Standardization; 1997.

[51] ISO-527-2 . Plastics - determination of tensile properties - part 2: Test conditions. ISO International Organization for Standardization; 1993. 
[52] Emara M, Torres L, Baena M, Barris C, Moawad M. Effect of sustained loading and environmental conditions on the creep behavior of an epoxy adhesive for concrete structures strengthened with CFRP laminates. Composites Part B: Engineering 2017;129:88-96.

[53] Yuan H, Teng J, Seracino R, Wu Z, Yao J. Full-range behavior of FRP-to-concrete bonded joints. Engineering structures 2004;26(5):553-65.

[54] Ali MM, Oehlers D, Griffith M, Seracino R. Interfacial stress transfer of near surface-mounted FRP-to-concrete joints. Engineering Structures 2008;30(7):1861-8.

[55] Monti G, Renzelli M, Luciani P. FRP adhesion in uncracked and cracked concrete zones. In: Fibre-Reinforced Polymer Reinforcement for Concrete Structures: (In 2 Volumes). World Scientific; 2003, p. 183-92.

[56] Lu X, Teng J, Ye L, Jiang J. Bond-slip models for FRP sheets/plates bonded to concrete. Engineering structures 2005;27(6):920-37.

[57] Bilotta A, Faella C, Martinelli E, Nigro E. Indirect identification method of bilinear interface laws for FRP bonded on a concrete substrate. Journal of Composites for Construction 2011;16(2):171-84.

[58] Ko H, Matthys S, Palmieri A, Sato Y. Development of a simplified bond stress-slip model for bonded FRP-concrete interfaces. Construction and Building Materials 2014;68:142-57.

[59] De Lorenzis L, Miller B, Nanni A. Bond of fiber-reinforced polymer laminates to concrete. ACI Materials Journal 2001;98:256-64. 
581

582

583

584

[60] Capozucca R. On the strengthening of RC beams with near surface mounted GFRP rods. Composite Structures 2014;117:143-55.

[61] Pan J, Wu YF. Analytical modeling of bond behavior between FRP plate and concrete. Composites Part B: Engineering 2014;61:17-25. 